\title{
La globalización del terror islamista: de Al Qaeda al Estado Islámico
}

Después del 11S, cuando las personas piensan en Al Qaeda, Estado Islámico (Daesh), Boko Haram, Ejercito de Mahdy, Hezbollah, Hamas, y otros grupos terroristas nacidos en Oriente Medio, generalmente dirigen su mirada hacia el islam. Así, la religión musulmana ha sido estigmatizada en Occidente, con base en los despropósitos que estos grupos han cometido en nombre del profeta Mahoma. No es admisible que esto ocurra, pero tampoco podemos culpar a los ciudadanos occidentales por tal desviación. Siendo Occidente una civilización judeo-cristiana -cuyos ciudadanos actuales no vieron ni vivieron los desmanes de su propia religión- es normal que hoy vean aterrados lo que se hace en nombre de otra religión.

El islam pasó de vivir y proclamar siglos de paz en su territorio, incluso pedir lo mismo para otras civilizaciones, a mutar en un catastrófico presente que hace que no se plantee aquel pasado pacifico por la obra siniestra de los grupos extremistas que desde inicios del siglo XXI han deteriorado profundamente la percepción de la religión de Mahoma en el resto del mundo.

Por supuesto que las circunstancias han cambiado mucho desde que el primer Estado islámico se propuso expandir su credo en 
todas las direcciones, o desde que gobernaba a toda la comunidad de sus fieles como única entidad política en estado de desafío latente para el resto del mundo. Las interacciones entre sociedades musulmanas y no musulmanas han vivido periodos de fructífera coexistencia y también etapas de antagonismo. Los patrones comerciales han estrechado los lazos entre los mundos musulmán y no musulmán, y numerosos acuerdos diplomáticos han surgido del trabajo conjunto de estados musulmanes y no musulmanes en pos de importantes objetivos compartidos. No obstante, el concepto binario del orden mundial continúa siendo la doctrina oficial del Estado en Irán, incluida en su Constitución, el grito de batalla de las minorías armadas en Líbano, Siria, Irak, Libia, Yemen, Afganistán y Pakistán, y la ideología de varios grupos terroristas activos en todo el mundo, entre ellos el Estado Islámico de Irak y el Levante (ISIL). (Kissinger, 2016).

Empero, dadas las nuevas perspectivas surgidas en todo el mundo acerca del tema, es pertinente ahondar un poco sobre esta religión con el fin de saber, sobre la base de una cultura histórica, qué terreno se pisa cuando se piensa en el islam:

El Islam constituye una religión monoteísta universal más joven del mundo. Fundada por el profeta Mahoma en la primera mitad del siglo VVII d.C., en la actualidad cuenta con cerca de $1.500 \mathrm{mi}-$ llones de fieles, repartidos por todos los rincones del planeta. Aunque fundamentalmente se concentran en un arco geográfico que arranca en mauritana, sobrevela todo el norte de África, se estira hacia Turquía, ensombrece las tierras de Oriente Medio, atraviesa Asia Central y declina en el subcontinente indio hasta toar las islas Filipinas e Indonesia, existen así mismo importantes comunidades en Estados Unidos y Europa, donde el crecimiento de esta fe ha sido espectacular en las últimas décadas. Al igual que en el África Subsahariana, donde el culto a Alá compite con el catolicismo y la pujanza de las nuevas iglesias evangélicas. En al menos 55 Estados del mundo -agrupados en la Organización de la Conferencia 
Islámica- es la religión oficial y la primera fuente de derecho. De ellos, únicamente 22 países -es decir, 3000 millones de habitantesconsideran que sus raíces son árabes (Martín, 2008).

A primera vista, no se observan razones para temer de un islam «militarizado» como el que vemos hoy; sin embargo, cuando sendos analistas hablan sobre la militarización de dicha religión se refieren a la yihad el llamado a combatir. Un llamado que hizo, en primera instancia, el egipcio Sayid Qutb, quien después de salir de las cárceles nasserianas animó especialmente a los jóvenes egipcios a una «ruptura islámica» que más tarde terminaría en una «reislamización desde abajo». Desde la muerte del profeta Mahoma, el islam sufre una serie de conflictos internos que lo divide en dos brazos principales: sunníes y chíes. Con sendas divisiones sectarias, estos grupos han desarrollado una guerra de poder con altibajos y momentos de menos tensión, en determinados periodos.

Durante los años setenta nace el terrorismo yihadista en Egipto. Es allí donde las primeras organizaciones intentan establecer un régimen islamista, mediante la creación de grupos como Al-Gama'a al-Islamiyya y Tanzim Yihad. Si bien estas dos organizaciones aún existen, no son las más conocidas. Ambas tuvieron como fundamento reislamizar a la sociedad egipcia, al tiempo que mantenían una enconada lucha en contra de los gobiernos egipcios. Hubo sin embargo un punto de inflexión en la profundización de la idea de reislamización: el Tratado de Paz firmado en 1979 entre el presidente egipcio Anwar Al Sadat y el primer ministro de Israel Menájem Beguín, que se selló con la devolución por parte de Israel de la península del Sinaí a Egipto, así como la aceptación del paso buques por el Canal de Suez y el reconocimiento del Estado de Israel por parte del Estado de Egipto.

La firma del tratado obtenido de las conversaciones de Camp David I fue el inicio del rompimiento entre el mundo árabe y el musulmán, que se vino a sellar con el asesinato en 1981 del presidente Sadat. Para entonces los grupos egipcios libraban una yihad particular contra el gobierno, mas no era su objetivo hacer una yihad global, menos aún se pensaba en la creación de un califato. Estos dos grupos yihadistas, que podrían ser llamados de inicio, no tienen hoy la fuerza 
para restablecer una yihad interna en Egipto; sin embargo, hubo posteriormente grupos terroristas que sí se iniciaron en la idea de una yihad, en principio regional, que consistía en la lucha contra los regímenes sunníes en su mayoría, tal fue el caso de la Yihad Islámica dirigida en Egipto por el médico Aiman $\mathrm{Al}$ Zawahiri. Este grupo juró lealtad a $\mathrm{Al}$ Qaeda posterior a los atentados del 11S.

El último de los altibajos dentro del Islam que vino a capitalizar la división más reciente ocurrió en Irán en 1979 con la Revolución Islámica de Jomeini, que vino a materializar la revolución chií y que representó una reislamización desde arriba, deponiendo al Sha Reza Pahlavi, tal vez el más importante socio de Occidente en Oriente Medio, con la pérdida del aliado iraní por parte de Occidente, Jomeini configuro un verdadero Estado Islámico, cuya base jurídica es la Sharia, donde se permitió la figura política del presidente, pero donde la figura preponderante es el Ayatolá, que es quien toma las decisiones.

La revolución islámica de Jomeini se adelanta una década al fin de la Guerra Fría. Es el inicio de una reforma del islam, no para modernizarse sino, por el contrario, para volver a los orígenes más primarios. No se puede hablar del islam actual sin antes mencionar este periodo de la historia reciente del mundo, la situación antes y después de la Revolución Islámica hace de Irán un país con características particularmente especiales:

La situación político-económica del Irán del sah presentaba, en primer lugar, características únicas y paradójicas. La fabulosa riqueza acumulada gracias al petróleo había permitido dotar a un país muy poblado de infraestructuras de todo orden con un amplio apoyo financiero. Al contrario que las de Egipto o Siria, las universidades iraníes de antes de 1979 no eran aparcamientos pasajeros para los desempleados del mañana. Los docentes, decorosamente remunerados, no soñaban con expatriarse para mejorar su nivel de vida, a consecuencia de lo cual pudieron formarse elites capacitadas. Los estudiantes prometedores hacían sus doctorados en los Estados Unidos, becados con fondos estatales. Dicho sea de paso, los más notables dirigentes y tecnócratas de la República Islámica se reclutaron entre estos graduantes de las universidades 
norteamericanas, que nunca dejaron de alentar sus propósitos [...] La originalidad de la situación iraní estriba también en otro hecho: los particulares vínculos entre los religiosos y el poder. En el islam chií existe una casi clerecía jerarquizada, dirigida por cierto número de doctores de la Ley aptos para interpretar los textos sagrados a su guisa. Este clero gozaba de una independencia enorme respecto al régimen. En el plano financiero había conservado la explotación de inmensas propiedades, haciendas sobretodo, pese a que el sah hubiera intentado arrebatárselas tras la "Revolución Blanca” de 1963. En términos ideológicos, la doctrina chií considera que quien ejerza el poder carecerá de legitimidad hasta el advenimiento del Imán oculto, el Mahdi, cuya llegada auguran los doctores de la Ley y a quien los chiíes deben obediencia, aunque, por razones de comodidad, puedan hacer al gobernante de turno concesiones pasajeras y formales que el clero, -si lo desease abstendrá de denunciar. (Kepel, 1995).

La referencia a la Guerra Fría es necesaria como punto de partida del yihadismo contemporáneo, es decir, a partir del momento en el que Osama bin Laden se erige como combatiente contra la U.R.R.S. con la financiación y apoyo de los Estados Unidos. A partir de allí se inicia la yihad contemporánea que, dejando atrás sus inicios primarios en Egipto, se inicia en Afganistán contra los soviéticos -con Paquistán como retaguardia- y posteriormente se vuelve contra quien la financió en sus inicios: los Estados Unidos. Hasta antes del fin de la Guerra Fría, solo la Revolución Islámica rompió con la potencia Occidental, cuando esta llega a su fin ocurre la retirada de los soviéticos de Afganistán (1989) y en general de los países musulmanes donde quiso imponerse.

La yihad se hace, en principio, para romper con los regímenes que gobiernan los países del mundo musulmán, en cuyo caso es permitido el uso de cualquier tipo de violencia en el nombre de Alá. Así funcionó en sus orígenes en Egipto y así funciona hoy en países donde la religión del islam es mayoría, esto incluye países de Oriente Medio y Próximo y países de África. En las mal denominadas «Primaveras Árabes» que fueron, en su gran mayoría, un fracaso en donde se intentaron. La idea fundamental era el derrocamiento de regímenes que ostentaban 
el poder durante décadas y desplazaron una rama del Islam para imponer otra, Siria, Libia, Bahréin; o como en el caso de Egipto donde gobernaba un régimen laico (Mubarak) y posteriormente a su derribo se impusieron los Hermanos Musulmanes, proscritos por Mubarak, derrocados a su vez por un militar laico, Abdelfatah Al Sisi, que hoy gobierna. Lo mismo intentó Qutb con Gamal Abdel Nasser. Vista en retrospectiva, no ha habido un cambio exponencial en la naturaleza de la yihad, hasta la llegada de Osama bin Laden.

\section{La nueva amenaza de la post Guerra Fría}

Cuando cae el comunismo en 1991, con el reconocimiento de Mijaíl Gorbachov de que era imposible seguir sosteniendo un sistema que había quebrado económicamente, y al quedar Estados Unidos como superpotencia, en solitario la nueva amenaza real a combatir fue el terrorismo. Esta forma de violencia, cuya naturaleza es religiosa, ha unido al mundo musulmán y occidental para hacer frente a su amenaza y luchar contra el mismo fenómeno. La nueva amenaza nace apenas terminado el comunismo y su máximo atentado es planificado en simultáneo con los cambios que se sucedieron en el mundo. En 1992 ocurrió el primer atentado contra las Torres Gemelas, por parte de una red yihadista, al mando del Jeque ciego Omar Abdel Rahman. Tras este ataque fallido, Al Qaeda inició la planeación de un nuevo atentado en esa ciudad, pero ahora con nuevos objetivos, entre ellos la sede de las Naciones Unidas, los túneles de Holland y Lincoln y nuevamente las Torres Gemelas; así lo registra en sus seguimientos a Osama bin Laden el agente de la CIA, Daniel Coleman.

Coleman fue un agente de la CIA entrenado para el espionaje durante la Guerra Fría. Una vez que terminó dicha guerra fue enviado a una vieja oficina en la estación Alec, cuyo nombre dentro de la agencia figuraba como Vínculos financieros terroristas. Allí su trabajo consistía en vigilar de forma exclusiva a un excéntrico millonario saudí dedicado a recaudar dinero para la yihad, antiguo «amigo» de los Estados Unidos que luego se distanció. 
Al Qaeda resurgió en el contexto de la post Guerra Fría con una ideología anti sistémica, alternando distintos ciclos de auges y caídas con diversos movimientos de izquierda (antiglobalización, altermundialistas, antiimperialistas, entre otros). La ideología de Al Qaeda, una reacción religiosa genuina, aunque relativamente manipulada o instrumentalizada, hizo frente a las realidades sociopolíticas vinculadas a los traumas de secularización y los autoritarismos, pero también al imperialismo norteamericano. (Ghotme, 2015).

La perspectiva de Ghotme choca con la realidad de Al Qaeda, pues la organización misma es de carácter imperialista, entonces pensar que esta libra una lucha exclusiva contra los Estados Unidos no tiene asidero cuando el propio bin Laden ofreció a sus seguidores un Califato Global. Es cierto que bin Laden tuvo siempre en la mira a los estadounidenses, pero su odio se extendió a sus aliados y la prueba son los atentados del $11 \mathrm{M}$ en la estación de Atocha del metro de Madrid en 2004, junto con los atentados en Londres el 7J de 2005, a tres estaciones del metro de Londres. También yerra Ghotme al afirmar que Al Qaeda era antiglobalización, pues nada más palpable que la globalización del terrorismo iniciada por esa organización.

Al Qaeda fue, bajo el mandato de bin Laden, una organización imperialista con fines de dominación global, que reivindicó un califato mundial como objetivo principal. Pretender obviar esto es errar en la realidad. Si hoy la organización no ha logrado su cometido es gracias a la guerra contra el terrorismo librada por los Estados Unidos y la OTAN, después de los atentados del 11S; de lo contrario estaríamos hablando no de un Califato estatal de Daesh entre Siria e Iraq sino tal vez de Al Qaeda por lo menos en parte del mundo.

Después de la post Guerra Fría, el primero en decir «aquí estamos» fue Al Qaeda que, como he dicho en párrafos anteriores, es el producto final de la misma Guerra Fría. En consecuencia, para analizar un delito convertido en fenómeno global es necesario mencionar las fases que 
llevan a una persona a convertirse en un muyahidín ${ }^{6}$. Un fenómeno que empezó a abrirse espacio dentro del mundo musulmán fue el Salafismo, que representa lo más profundo del islam, según sus intérpretes.

El fundamentalismo islámico, o Salafismo, es una vuelta a las fuentes, a los fundamentos originales, sometiendo al considerado "islam deformado" a una revisión, y a una limpieza, de tradiciones posteriores que, a juicio de los salafistas, han desvirtuado la naturaleza y el sentido estricto en la aplicación de la Ley Islámica, así como su interpretación con el paso del tiempo y las sucesivas generaciones. Esta pérdida y desvirtualización se la atribuyen a la propia umma por ignorancia, superstición, desconocimiento y olvido de las esencias originales y a los herejes, o apostatas, por su mala influencia. Durante el desarrollo de la historia, la sociedad musulmana o umma ha sufrido diversos avatares que la han llevado desde la expansión más gloriosa, en los primeros años de su existencia (y en los siglos XVI-XVII con la expansión de los imperios otomano, safaví y mogol) hasta la pérdida de territorios y prestigio. Este proceso de glorificación, y posterior decadencia, ha quedado marcado en el ideario musulmán para tomar conciencia de tal evolución en el siglo XIX y principios del XX. La existencia y el activismo de pensadores, y estudiosos, así como la propia sociedad islámica, han buscado razones por las que se ha llegado a esta situación. De todas ellas se pueden destacar dos. Primera, la sociedad islámica (umma) recibe un castigo divino por no cumplir con las normas, esto conlleva el abandono, la falta de la confianza de Alláh, y la pérdida del esplendor pasado. Y segunda, la existencia, y expansión, de los no creyentes que durante siglos además de menospreciar los valores del islam, han sometido a sus seguidores a situaciones de ostracismo, olvido, humillación, abuso, explotación o matanzas. De cualquiera de las dos formas, se llega a la conclusión, por parte de la umma, de la necesidad de retomar los valores iniciales de islam, de volver a los fundamentos y de imitar

6 Combatiente de la yihad. 
los comportamientos del Profeta Muhammad, de los Cuatro Califas Bien Guiados o rachidum y de las generaciones coetáneas denominadas shahaba. En el razonamiento de que, la expansión inicial se debió a tener el apoyo divino gracias al cumplimiento de la norma divina y al desarrollo de un comportamiento que respondía a esta norma. Por lo tanto, para retomar esa situación se debe volver a ese comportamiento. A este movimiento se le denomina Salafismo, en referencia al término salaf (primeras generaciones). El movimiento salafista pretende, por tanto, recuperar esa confianza de Alláh y con ello recuperar el esplendor que el islam nunca tuvo que perder. Cabe distinguir el término Salafismo de salafiya, el cual se refiere a un movimiento intelectual de finales del XIX y principios del XX, que tenía como objetivo devolver al islam su esencia original dentro del entorno de la modernidad reinante. (González, 2015).

Estamos entonces ante una «regresión» del islam al periodo de sus inicios, es decir, a la aplicación de la Sharia al pie de la letra. Con respecto a esto último, vale la pena decir que no ha habido una reforma dentro del islam; por tanto lo que nos encontramos hoy día es una atomización, una crisis dentro del islam. La multiplicidad de movimientos surgidos dentro de la religión, que si bien tiene su gran división en sunníes y chiíes, no se limita a esta. Las subdivisiones dentro de estos dos brazos ha profundizado como forma de "purificación» la práctica de la misma religión y eso ha conllevado imprimir la acción militar, que mayormente es empleada por las subdivisiones sunníes, no por ello quiero decir que ocurra de forma ínfima dentro del chiismo, aunque es justo afirmar que el chiismo apenas después de la Revolución Islámica tiene pretensiones expansionistas y militares en Oriente Medio.

\section{Radicalización militar del islam}

Este fenómeno consiste en lo que clérigos, filósofos y fieles de esa religión consideran una desviación dentro del islam: la utilización del Corán para fines para los que no fue escrito, lo que constituye una 
ofensa a la memoria del profeta Mahoma. Para estudiosos occidentales -curiosamente- consiste en la transformación a la violencia de jóvenes musulmanes por culpa de Occidente. Es recurrente encontrarse con un lenguaje de culpabilidad occidental desde el propio Occidente que arguye el pasado para atenuar el terrorismo; la intervención de ingleses, franceses y belgas en tierras musulmanas, entre otros, son solo algunas de las disculpas que intelectuales y líderes occidentales utilizan para este fin.

De una forma más cercana usan la intervención de Estado Unidos y la OTAN en Iraq para apremiar a la disculpa del islam militar, sin siquiera mencionar la religión como motivo supremo del terrorismo islamista en suelo occidental. La situación es tal que se ha hecho normal que una vez que ocurre un atentado yihadista en suelo occidental los mismos gobernantes disculpan el atentado arguyendo la frase que ya ha hecho carrera: «el islam es una religión de paz». Esta frase la pronunció el primer ministro, David Cameron, cuando yihadistas decapitaron a un miembro de las Fuerzas de Seguridad en una calle del sudeste de Londres; igualmente la pronunció el presidente, François Hollande, con ocasión de los atentados a la revista satírica Charlie Hebdo y la volvió a pronunciar en los atentados posteriores en 2016 en París en la sala Bataclan.

La religión islámica desarrolló en su interior muchos brazos militares después de los atentados del 11S; sin embargo, Occidente, a diferencia del mundo musulmán, insiste en ignorar esta realidad, que es además la región del mundo más castigada por el yihadismo, pero también la que más yihadistas produce. Los integrantes de grupos yihadistas reciben entrenamiento militar, esto, aunado a la reivindicación que hacen de la religión, hace que se materialice una combinación en extremo violenta.

\section{El wahabismo}

Es dentro del ala sunní, el brazo militar y económico que posiblemente más connotación ha venido mostrando en las últimas décadas, el wahabismo tiene su origen en Muhammad ibn 'Abd al-Wahhab en el 
siglo XVIII. El propio wahabismo ha sido blanco de críticas desde su origen, y no fue un ala sunní que tuviera una gran repercusión en sus inicios; sin embargo, cuando estrecharon lazos con la dinastía Saud ese vínculo ideológico político relanzó al wahabismo a la obtención de un poder supremo desmesurado. El poder del petróleo a nivel global, la profundización de la pureza del islam dentro de las sociedades donde residen sus seguidores, junto con la intención histórica (venida desde la monarquía saudí) de expandir el islam por todo el mundo, son solo algunas de las repercusiones que se han obtenido gestionando grandes sumas de dinero en sociedades sunníes dentro de Occidente.

Esto ha llevado a la radicalización de sus seguidores, a través de la predica intolerante de imanes en las mezquitas occidentales que son mayoritariamente construidas con dinero saudí y cuyos imanes deben ser nombrados por ellos mismos. Los miembros de la monarquía saudí, la familia Saud es de origen wahabí, de ahí su interés en financiar por el mundo está ala del islam.

\section{El salafismo}

Nace de la misma columna vertebral del wahabismo, sin embargo, se distancia de los segundos por considerar que limitan su importancia y lo hacen parecer como una rama dentro del propio wahabismo, algo que ellos se niegan a aceptar. Los salafistas no se remiten únicamente a la figura del profeta Mahoma dentro del islam, pues esta rama sunní también toma dentro de su ideario purista el comportamiento de los «discípulos» de Mahoma, de quienes lo acompañaron de cerca en esa primera generación del islam. Para los salafíes apelar a los inicios de la religión les diferencia del resto, así como la aceptación no solo del profeta sino del comportamiento de sus primeros seguidores marca la diferencia entre ellos y los wahabís. Los salafíes se atribuyen la representación del islam "puro» de los primeros tiempos, ese que el profeta predicó en vida.

El fundamentalismo islámico, o salafismo, es una vuelta a las fuentes, a los fundamentos originales, sometiendo al considerado "islam 
deformado" a una revisión, y a una limpieza, de radiciones posteriores que, a juicio de los salafistas, han desvirtuado la naturaleza y el sentido estricto en la aplicación de la Ley Islámica, así como su interpretación con el paso del tiempo y las sucesivas generaciones. (Hernández, 2015).

El salafista estructura su discurso en lo que los discípulos e intérpretes del profeta escribieron en el Coral, pues el propio profeta nunca escribió, en tanto que esto les permite hacer su propia interpretación, en este caso, llevar a la práctica el Islam de los años seiscientos después de la muerte de Mahoma.

\section{Los takfiries}

No son distintos a las dos versiones del islam mencionadas anteriormente, es más, hay que decir que son distintos nombres para una misma visión purista de la religión; sin embargo, es complejo referirnos a escuelas dentro del islam, pese a que existen expertos que estudian dicha religión desde el punto de vista de las escuelas. En cambio no es descartable hablar de teorías con base en jurisprudencias teológicas interpretativas de la religión. Takfir significa considerar incrédulo al otro, Al Qaeda hace parte de esta última edición del islam, fue notorio y publicitado su incitación a la purificación del islam señalando a sociedades musulmanas como apostatas e infieles igualándolas en su ideario a sociedades occidentales, los casos precisos son los de Arabia Saudí y los Estados Unidos. Para los takfiries la yihad verdadera consiste en expulsar al invasor de la tierra del islam, de hecho, el distanciamiento entre bin Laden y los Estados Unidos tuvo su origen en esto pues el pacto entre ambos consistió en expulsar a los soviéticos de Afganistán y que nadie volviera a ocupar ninguna otra tierra musulmana.

Dentro de estas tres ramas del brazo sunní no existen mayores diferencias, de hecho son un pensamiento que emana de una misma base; tal vez las diferencias radican en la forma como puede purificarse el islam y para ello utilizan el terrorismo como forma de castigo a quienes denominan apostatas e infieles. No obstante, dentro del 
propio islam surgen voces críticas a esta forma de pensamiento que argumentan que estos grupos son una minoría, que sin embargo tiene un poder económico que hace difícil pensar que sus actos terroristas puedan llegar a tener un fin próximo. Estos críticos filosóficos hablan de una desviación del islam que hizo que se perdiera su realidad humanista y pacífica, la misma que el profeta le imprimió en sus inicios. Pero sin duda el gran enemigo declarado del wahabismo es el chiismo.

A pesar de lo anterior, los chiíes no son ajenos a esta batalla por la prevalencia dentro del mundo musulmán como centro de poder desde donde se ilumina el islam. La modernidad agresiva de este brazo de la religión coránica inició en 1979 en Irán, con el retorno del Ayatola a tierra persa y el derrocamiento del Sah Reza Pahlavi; a partir de allí comenzó el empoderamiento financiero desde ese país hacia grupos que posteriormente llegaron a tener en sus manos, prácticamente, el poder del Estado.

Hezbollah es el modelo de grupo terrorista creado por el régimen de los ayatolas. Dicho modelo sustituye la acción del Estado sobre la población y fue replicado por el Hamas palestino con la financiación iraní. La gratuidad de la educación, la salud y en ocasiones hasta de la alimentación son solo algunos de los sectores que este islam usa como modo de afincar la lucha contra el brazo sunní en sociedades musulmanas.

Sin embargo, el islam chií ha ido en crecimiento y hoy libra una guerra interna dentro de la religión contra sus más enconados enemigos, los sunníes. Si antes se trató apenas de la supervivencia de los «seguidores de Ali», hoy se trata de la supremacía religiosa y política dentro del mundo musulmán. Con la implementación de un Estado Islámico por excelencia, la teocracia chií no solo se instauró en Irán para quedarse sino para expandirse y formar en distintos territorios musulmanes una especie de ejércitos accesorios para los Guardianes de la Revolución. El caso del Hamas palestino viene a romper todos los esquemas dentro del islam, siendo este una derivación de los Hermanos Musulmanes egipcios de Hassan Al Banna y Sayyid Qutb, la «necesidad» hizo que estos sean un apéndice persa del islam.

El terrorismo radical islamista siempre ha estado en el Líbano, prácticamente ha sido un Estado dentro del Estado. Desde entonces, y hasta nuestros días, ha formado un Estado Comunitario que le ha 
proporcionado una alta popularidad y que no le permite al stablishment combatirlo, por lo que ha sido el actor que se apropió del discurso que los gobernantes árabes abandonaron, y que sigue alentando el discurso nacionalista entre los palestinos y agitando la masa social, acogiendo a sus cabecillas en su territorio y en una estrecha relación con Hamas. De igual forma lo hizo entonces y lo hace hoy Siria, país que también acogió a los radicales palestinos que aún permanecen en su territorio.

Hamas está reduciendo al mínimo su presencia en Damasco, donde hasta la fecha el grupo radical islamista palestino tenía su principal base fuera de Gaza. Fuentes diplomáticas han filtrado a Reuters que la «bestia negra» del estado de Israel está desde hace semanas llevando a cabo un desalojo de sus dirigentes en la capital siria que en su día llegaron a contarse por centenares-, para hacerles retornar a la franja de Gaza. (De Andres, 2011).

\section{El caso palestino}

Hablar del conflicto israelí-palestino sin hablar de religión es hablar de otra cosa, afirma el catedrático de la Universidad Hebrea de Jerusalén, Gabriel Ben Tasgal (2014). En mi criterio, esto va más allá e incluye toda una sociedad musulmana haciéndose más beligerante y dejando un mayor número de víctimas entre los mismos musulmanes, al tiempo que se extiende a Occidente como infieles y apostatas frente al islam. Esa misma radicalización beligerante entre sunníes, chiíes y sus extensiones militares llegó a Occidente y no parece que sea por poco tiempo, la primera década del siglo XXI fue el inicio del castigo a Occidente, continua hoy en mitad de la segunda década del mismo siglo y no hay visos de que esto acabe pronto.

La radicalización del sujeto necesita una profundización encaminada a los orígenes de la religión y, aunque intelectuales occidentales disculpen sistemáticamente el yihadismo como resultado de una supuesta opresión occidental al mundo musulmán endilgando una causa política, lo cierto es que esto tiene que ver más con la parte religiosa que con cualquier otra motivación. Uno de los lugares determinantes 
de la radicalización es la mezquita -hoy denominadas Centros Culturales- y la red social -entendida esta como sociedad de personas dentro de un territorio (escuelas, barrios, etc)-. Pero lo anterior hace parte de la radicalización en Occidente, pues en el mundo musulmán no se necesita una red local, una mezquita o una escuela para estos fines, allí las versiones fundacionales coránicas bastan para estos efectos.

El radicalismo islamista palestino, y luego el del grupo terrorista Hezbollah, adquiere unos ingredientes añadidos a parte del nacionalismo que mencione anteriormente. En primera lugar, está la carga simbólica de ser la «víctima» que ha sido expulsada y que tiene que compartir su territorio con el "victimario", cuestión que la diferencia del resto países de su entorno islámico. En segundo lugar, está la carga "mediática», en especial dentro de un mundo globalizado donde el conflicto se ha reducido a buenos y malos, por lo cual la suma de ambos ha venido a polarizar el tema de forma global corriendo el riesgo de sobrepasar la delgada línea entre la defensa-terrorismo y la crítica-apología del terrorismo.

Cuando Egipto y Jordania logran sendos acuerdos de paz con Israel la cuestión palestina pasa a convertirse en el casus belli del terrorismo libanés en cabeza de Hezbollah y, posteriormente, de grupos terroristas como Al Qaeda que toman la causa palestina como la causa de su lucha contra la «Entidad sionista» y sus aliados occidentales. Sería conveniente que la ANP rechazara de manera tajante todos y cada uno de los discursos terroristas que combinan sus acciones con la causa palestina como justificante de las mismas.

Estos mismos nacionalismos han transformado las sociedades de distintas formas, y generalmente de la represión surgen los propósitos de libertad. Es ese momento en el que el punto neurálgico (método) suele transformarse de un estado de paz dentro de la represión, precisamente logrado por ésta última, a un estado de violencia que en determinados casos degenera en terrorismo.

Estos grupos radicales islamistas generalmente utilizan una reivindicación socio-política para justificar su accionar terrorista. Así como lo han hecho con el caso palestino, también lo han hecho con la reivindicación de Al Andaluz y la necesidad de su recuperación, que lleva implícita la amenaza a países europeos; en su momento, esta 
reivindicación la hizo bin Laden y más frecuentemente la utilizó el segundo al mando, $\mathrm{Al}$ Zawahiri. La utilización del terrorismo como vía para solucionar conflictos obvia otras posibilidades de llegar al objetivo de la paz. El terrorista asume la efectividad de llevar a la población o parte de ella a un estado de violencia máximo, de forma que paralelamente pueda convocar la urgencia de poner fin a estos actos llevados a cabo por ellos mismos.

El apoyo de bin Laden a la «causa palestina» advierte un componente curioso, aunque coherente con su perspectiva islamita, el emir no coincidió con Fatah ni Hamas, aunque este último utilizara sus mismos métodos yihadistas.

Al Qaeda, cuya oposición al nacionalismo palestino es antigua y bien arraigada, históricamente solo pudo reclutar miembros palestinos dentro de las comunidades exiliadas en el Golfo. La virulenta hostilidad contra la OLP, inspirada en la denuncia de sus tesis "marxistas" por Abdallah Azzam, se agravó por el compromiso de Yasser Arafat y su grupo Fatah, en el proceso de paz con Israel. Al Qaeda asimilaba a la Autoridad Palestina, establecida en Cisjordania y Gaza a partir de 1994, a los regímenes "apostatas” que libran el mundo árabe a los "judeo-cruzados". La organización de bin Laden fue apenas un poco más indulgente con Hamas, el rival islamista de Fatah, puesto que esa organización no pensaba proseguir la "lucha armada" más allá de un marco geográfico circunscrito a Israel y los territorios palestinos. Este rechazo a exportar el conflicto palestino era inaceptable para la lógica expansionista de la yihad mundial. Además, Hamas emergió de la rama palestina de los hermanos musulmanes, de los que Zawahiri no dejaba de censurar los compromisos y renuncias. (Filiu, 2011).

El caso palestino singulariza dentro de la yihad un capítulo que podría llamar «aparte», pues dibuja la división interna de la religión islámica en un contexto realista, ya que los intereses que mueven a los distintos grupos, al no ser los mismos, profundizan las diferencias entre unos y otros. Una especie de «egoísmo» táctico, pues mientras 
bin Laden reprocha a un grupo su iniciativa pro-Occidental (Fatah), condena al otro por llevar a cabo una yihad propia, local (Hamas).

Las tentativas de Al Qaeda para infiltrarse en Cisjordania y Gaza fueron abortadas por los servicios secretos de la Autoridad Palestina, y también por los militantes de Hamas, lo que acentuó el contencioso entre los partidarios de bin Laden y los nacionalistas islámicos. Al Qaeda se vio reducida a agitar el estandarte de la causa palestina y de la "liberación de Jerusalén", a partir de Iraq o de Pakistán. (Filiu, 2011).

Aunque Al Qaeda desarrolló un contencioso ideológico respecto a los palestinos de los territorios de Gaza y Cisjordania, esto no impidió que palestinos residentes en campamentos de refugiados en Líbano, Siria o Jordania entraran en sus filas, como sucede con los que engrosan las filas de Hezbollah. Es un sentimiento de descontento respecto de ambos grupos palestinos, lo que ha llevado a los residentes en estos campamentos a adherirse a la entonces yihad global de Al Qaeda. El no conseguir la AP el reconocimiento de un Estado palestino, por un lado, y el no desaparecer a los israelíes de su territorio por parte de Hamas alentaron y siguen alentando este descontento, que siempre ha favorecido a llenar las filas de Hezbollah, y seguramente llenará las filas de otros futuros grupos terroristas que surgirán mientras este conflicto exista.

Otra de las razones que ahondó el contencioso entre Al Qaeda y los grupos palestinos fue que paradójicamente en amos vio una occidentalización pues nunca estuvo ni está de acuerdo con dejar la toma de decisiones políticas a los individuos; pues esto va en contra de la naturaleza de un califato. El Califa es quien ordena y los individuos deben cumplir. El hecho de celebrar elecciones en los territorios palestinos nunca fue bien visto por bin Laden ni lo es hoy por Zawahiri; tampoco la idea de implementar instituciones políticas similares a las occidentales es vista con agrado por el grupo yihadista, todo esto a pesar de que el líder ${ }^{7}$ de Hamas constantemente llama a la Yihad.

7 Ismail Haniyeh. 
Sin embargo, que se celebren elecciones no quiere decir que en los territorios palestinos haya una democracia. En 2006 fue la última vez que se acudió a las urnas y en Cisjordania -donde se espera un gobierno pro-occidental- se reprocha a Mahmud Abbas la intención de perpetuarse en el poder como Arafat, pero sin su carisma. Los caudillos nacionalistas no monárquicos, por los que tradicionalmente ha sido gobernado el mundo árabe, lo han hecho en franca distancia con la democracia y regularmente bajo el paraguas de una política antioccidental. No ha sido distinto en el caso palestino, en donde la retórica radical islamista, en el caso de Hamas y antes en la OLP, no reconoce en su sociedad el sistema democrático creíble, pues lo considera un sistema distorsionado cuyo modelo es occidental, lo cual va en contraposición con su propio sistema.

Estos caudillos que tienden a gobernar por décadas y que reprimen a su propia población, no tienen mayor margen en su discurso que no sea la protección que ellos le brindan al pueblo contra el «invasor» que es identificado como el único enemigo y que está representado en la zona por Israel. Dentro del sistema del caudillismo difícilmente habrá un espacio sólido para la convivencia pacífica en la región, así como tampoco para la educación y superación de su propia población. Incluso, en algunos casos, el nacionalismo va inmerso desde los inicios de la etapa escolar, coartando así la posibilidad del individuo para hacer su propia elección o decidir un proyecto de vida.

En el discurso político palestino, el nacionalismo está tanto en Fatah como en el Hamas. El primero era dueño de un discurso moderado acerca de la creación de un Estado Palestino laico; mientras que el segundo, desde su carta fundacional, menciona la necesidad de un Estado Palestino islámico donde se gobierne con la Sharia, y específicamente niega la existencia de un Estado judío del que además menciona la necesidad de expulsión del territorio palestino. Cuando Hamas habla de una expulsión de la entidad sionista de los territorios palestinos no se refiere solo a Gaza y Cisjordania, realmente hace alusión a todo el territorio israelí, el cual reclaman como propiedad de sus antepasados. El nacionalismo, por lo tanto, es una pared sólida, que sirve de identificación profunda cultural, lo cual ha hecho más 
difícil aún la consolidación ya no solo de una paz duradera y sostenible en la zona, sino la continuidad de la negociación con miras a la consecución de la paz.

El discurso de Fatah no es menos nacionalista, aunque sí más moderado, pues ha pasado de un inicio religioso a una dialéctica netamente política; su nacionalismo tiene bases políticas, distinto al de Hamas, que se apoya en el islam para proclamar tal nacionalismo. Hamas va más allá y aspira a un Estado palestino islamizado bajo la figura de un califato. En dicho Estado no se vislumbra la posibilidad de que otras religiones puedan habitar en su territorio, pues toda su cultura y su sociedad debe ser islámica, arropándose así en un discurso nacionalista de carácter religioso. Al mismo tiempo, dentro de ese discurso nacionalista la negación de Israel como Estado traza la línea política de su nacionalismo, pues para Hamas no existe posibilidad de que un Estado Palestino comparta territorio con quien ellos definen como el invasor de la tierra.

El territorio y el nacionalismo desde el punto de vista del Movimiento de Resistencia Islámica en Palestina:

Artículo 12. El nacionalismo, desde el punto de vista del Movimiento de Resistencia Islámica, forma parte del credo religioso. Nada es más significativo o más profundo en el nacionalismo que en el caso de que un enemigo pise tierra musulmana. Resistir al enemigo y eliminarlo pasa a ser el deber individual de todo musulmán, hombre o mujer. Una mujer puede marchar a combatir contra el enemigo sin el permiso de su marido, igualmente el esclavo, sin el permiso de su amo. Nada semejante se encuentra en ningún otro régimen. Esto es un hecho indiscutido. Mientras que otros movimientos nacionalistas están ligados a causas materialistas, humanas o regionales, el nacionalismo del Movimiento de Resistencia Islámica tiene todos esos elementos, así como el elemento más importante que le da alma y vida. Está ligado a la fuente del espíritu y al dador de la vida, izando en el cielo de la nación el estandarte celestial que une tierra y cielo con fuerte atadura. (Hamas, 2011). 
El nacionalismo, representado en Fatah y en Hamas, ha hecho hasta ahora imposible pensar en un acuerdo de paz entre israelíes y palestinos. El terrorismo palestino del Hamas ha mutado nuevamente, pasó de una Intifada de las piedras en 1985 a una Intifada más violenta de cohetes y terroristas suicidas en 2005, a lo que hoy su líder Ismail Haniya a denominado la "Intifada de los cuchillos" que ha consistido en el asesinato selectivo de israelíes en lugares públicos por parte de lobos solitarios que se auto radicalizan y actúan -en muchos casos- sin una conexión directa con el terrorismo. El radicalismo del Hamas se universalizó dentro de la población de Gaza, de esta forma echó mano de todo un entramado que involucra todas las estructuras de esa sociedad: familia, escuelas, mezquitas, calles, etc.

\section{El origen de la globalización}

\section{Al Qaeda (La Base)}

La Base, con esa denominación fue fundado el mayor grupo terrorista conocido hasta la primera década del 2000, el único grupo con aspiraciones planetarias que el mundo haya conocido. Pakistán, el país de origen de Al Qaeda, es la base, el origen del terror global, el lugar desde donde se inició, organizó y emprendió una guerra contra la Unión Soviética, entonces ocupando Afganistán una década antes que esta desapareciera.

En 1986 millones de refugiados afganos habían huido a la provincia de la Frontera del Noroeste de Pakistán, convirtiendo su capital, Peshawar, en la principal plataforma de acceso a la yihad contra la invasión soviética. Las calles de la ciudad eran un bartiburrillo de lenguas y vestimentas de diferentes nacionalidades, y emanaban un extraño y excitante cosmopolitismo que hechizaba a todo el que transitaba. En ella se establecían cooperantes, mullahs independientes y agentes secretos de todo el mundo. La afluencia clandestina de dinero y armas provocó un verdadero 
auge económico en la ciudad que siempre había vivido del contrabando [...] Los señores de la guerra afganos trasladaron a sus familias a la ciudad universitaria, donde residía la clase profesional entre eucaliptos y magnolios. Los señores de la guerra se enriquecieron embolsándose parte de las subvenciones de los saudíes y los estadounidenses ${ }^{8}$. Sus sanguinarias rivalidades, ${ }^{9}$ junto con los atentados y asesinatos semanales de la KGB y la KHAD (el servicio secreto afgano), hicieron que la cifra de comandantes afganos muertos fuera mayor en Peshawar que en el campo de batalla [...] Cuando venció su contrato con la clínica de Yidda, el doctor Ayman al-Zawahiri se incorporó a la creciente comunidad árabe de Peshawar. Mas rollizo que en sus vidas previas alardeaba de que Pakistán era como su "un segundo hogar" ${ }^{10}$ para él ya que de niño había pasado algún tiempo en el país cuando su abuelo materno ejercía allí de embajador de Egipto. (Wright, 2011).

Mientras que durante su estadía en Pakistán, Al Zawahiri pasa de trabajar en una clínica privada a un hospital de la Media Luna Roja, auspiciado por Kuwait; Bin Laden era expulsado de su país natal, Arabia Saudí. Se desplazó a Sudan, entre otros países de África, hasta recalar en Pakistán donde encontraría a su aliado en la refundación de la yihad global que hoy conocemos, y posteriormente asentarse en Afganistán durante el gobierno Talibán del Mullah Omar.

Con los inicios de Al Qaeda estamos frente a la denominada por Osama bin Laden, yihad global, que no es otra cosa que la militarización del islam por parte de una facción sunní del vasto mundo musulmán. Esta nueva yihad viene a romper todos los esquemas del terrorismo internacional que ya antes habíamos conocido y que nació

8 Entrevista a Marc Sageman. Sageman rebate la afirmación común de que los comandantes se estaban enriqueciendo con el tráfico de heroína. Fuente: La Torre Elevada. Al Qaeda y los orígenes del 11s. Lawrence Wright.

9 Entrevista con Rahimullah Yusufzai. Fuente: La Torre Elevada. Al Qaeda y los orígenes del $11 \mathrm{~s}$

10 Entrevista con Yamal Ismail. Fuente: La Torre Elevada. Al Qaeda y los orígenes del 11s 
del terrorismo palestino, Septiembre Negro, Fatah, OLP, cuyo accionar se hizo global porque materializó actos terroristas a nivel internacional, de tal magnitud, que concentraron toda la atención mundial. El secuestro sistemático de aviones desde aeropuertos en Europa, la matanza de atletas israelíes en las Olimpiadas de Munich, entre otros, era hasta ese momento lo más atrevido que conoció el mundo en cuanto al terrorismo musulmán.

Sin embargo, bin Laden, que también apoyó la causa palestina, estaba decidido a castigar a los infieles de todo el mundo, iniciando por el propio mundo musulmán, donde los combates locales entre grupos salafistas ya eran cosa de todos los días. Al mismo tiempo, Osama profesaba la instalación de un califato global del cual él sería el jefe.

Según Muhamad Mahmud Ould Muhamadu, director asociado del Programa Humanitario e Investigación de Conflictos de la Universidad de Harvard, el nacimiento de Al Qaeda fue consecuencia del fracaso de los desacreditados Gobiernos árabes a la hora de defender sus propios países. Su evolución posterior, argumenta, fue producto de una doble conclusión: los extremistas percibieron que estos regímenes eran demasiado débiles como para defender a sus ciudadanos, pero igualmente fuertes como para ser derrocados [...] Así la historia de la organización se puede segmentar en tres fases. La primera, embrionaria, entre 1989 y 1996. En ella, además de sentar las bases teóricas para la yihad internacional. Al Qaeda pudo levantar su infraestructura militar, imponer una disciplina única, un método propio de entrenamiento y una cohesión cimentada en la lealtad islámica. Su estructura de mando era aún piramidal: a la cabeza se situaban Osama Bin Laden y Aiman al Zawahiri, asesorados por un Consejo de Shura compuesto por 31 personas, y dividido en cinco comités operativos: uno militar, otro para asuntos religiosos, un tercero para cuestiones económicas, un cuarto para la propaganda y un quinto encargado de la logística. Abu Obaida al Banshiri y Muhamad Atef, ambos caídos en batalla, fueron los comandantes responsables de levantar los campamentos en Afganistán y Paquistán, tanto en Kabul como en Jost, 
Jlalabad, Tora Bora, Kandahar, Liza, Kunar y Mahavia, así como de coordinar la formación de las células en el exterior, principalmente en Filipinas, Kenia, España, Alemania y el Reino Unido. Se calcula que, en ese tiempo, entre 10.000 y 20.000 combatientes fueron cualificados para integrar e incluso formar sus propias células terroristas [...] la segunda fase, centrada en la estrategia de guerra. En 1996, distribuyo entre sus militantes la denominada Enciclopedia de la yihad, un manual de comportamiento y actuación que alcanzó enorme difusión cuando tres años después fue vertido en soporte digital y volcado en Internet. En él, además de las técnicas en el uso de diferentes armas y explosivos, se enseñaba al combatiente a soportar los interrogatorios, a infiltrarse en las sociedades infieles y contactar con otros muyahidines sin ser descubierto. Este documento es una de las claves del éxito global de Al Qaeda y sus distintas versiones han inspirado, y aun inspiran, a decenas de células, que gracias a su sencillo acceso no necesitan un vínculo directo con la organización madre. (Martin, 2008).

Las dos primeras fases fueron anteriores al gran atentado que daría a Al Qaeda la máxima popularidad, y que la convirtió en la «marca» por excelencia del terrorismo internacional. La organización del entramado militar del islam y posteriormente la propaganda para conseguir miles de militantes dentro de la yihad hicieron de Al Qaeda el grupo terrorista con más ambiciones de a historia. Ya entonces, Bin Laden hablaba de la necesidad de llevar a cabo operaciones de envergadura, pero para ello se requería tiempo y con ello paciencia, no así las operaciones de "bajo calado" como él llamaba. Llama la atención el tiempo que transcurrió entre el inicio y organización de Al Qaeda y sus golpes más grande, el 11S (2001) y posteriormente los atentados en Madrid (2004). Sin embargo, posterior a la ejecución de sus máximos atentados, la organización inició una etapa de decadencia que la fue desplazando por el hoy conocido ISIS o DAESH.

El violento compás de espera que medió entre ambas operaciones constituyo el núcleo de la denominada tercera fase, en la que se 
reagruparon y se redefinieron estructuras y objetivos. El entramado piramidal cedió el mando operativo a un nebuloso grupo de unidades regionales independientes que actuaban con el mismo espíritu y el marchamo de la célula madre, aunque sin conexión directa con la misma. (Martín, 2008).

Osama bin Laden, a través de Al Qaeda, rompió todos los esquemas del terrorismo e implantó el terror global ${ }^{11}$, nos dejó claro que después del $11 \mathrm{~S}$ ya nadie estaría seguro en ningún lugar del mundo. No obstante, el Emir encontró opositores dentro de su propio grupo, pues antes de los atentados en New York Al Qaeda libraba una lucha interna en Afganistán, había en ese país un liderazgo que se erigió contra Al Qaeda y sus socios Talibanes, y que ya antes había luchado contra los soviéticos y los había derrotado. Empero, es necesario aclarar que Talibanes y Al Qaeda no compartían los mismos valores, aunque sí el mismo enemigo, Occidente.

Ahmad Sah Masud, líder de la denominada Alianza del Norte, fue el hombre que enfrentó a bin Laden sin lograr vencerlo; posteriormente, el Emir de Al Qaeda ordenó su asesinato dos días antes del 11S. Masud había advertido a Occidente sobre el peligro que representaba Al Qaeda, pero este solo vino a comprobarlo cuando ocurrieron los atentados en New York, y los sucesivos en Europa, podría decirse que fue el aliado occidental que no recibió el apoyo necesario para acabar con Al Qaeda antes que esta se hiciera global. El costo económico de la operación terrorista del 11S fue de 500.000 dólares, pero el costo para Occidente después del atentado ha sido enorme, y no hay visos que esto vaya a parar en un futuro próximo, porque el terrorismo no desaparece, muta; mientras tenga la ventaja de la sorpresa, mientras las Agencias de Inteligencia de las potencias occidentales no trabajen de común acuerdo y mientras Occidente no mire la realidad de su alrededor el terrorismo tan solo mutará, como se verá en los próximos párrafos.

11 Hasta ese momento, Al Qaeda fue la única organización terrorista con aspiraciones mundiales. 
A partir del 11S, Al Qaeda se convirtió en una serpiente de muchas cabezas, ingobernable desde una central, convertida en «franquicias» gracias al éxito conseguido en suelo estadounidense. Pese a que, a partir de 2004, bin Laden ya no era el eje de Al Qaeda seguía siendo para los muyahidines la inspiración, por él sentían admiración. Osama bin Laden tuvo la influencia que le concedió su marca: Al Qaeda, una influencia obtenida luego del 11S. El cuestionado Emir fue el primero en el punto de mira de los Estados Unidos. Así, una vez ocurridos los atentados, Al Qaeda terminó convertida en la empresa criminal más grande del mundo, esto se vio materializado en la transformación en franquicias, pero nunca abandonando lo que hoy conocemos como Al Qaeda Central cuyas operaciones son planeadas y dirigidas desde Pakistán.

La transformación del grupo en franquicias llevó necesariamente a que -una vez iniciada la llamada "Guerra contra el terrorismo" del presidente George W. Bush y sus aliados occidentales- el grupo surgiera en contraposición a esta en los mismos lugares de la guerra, Irak y Afganistán. A partir de los atentados del 11S, dada la magnitud de los mismos, Al Qaeda empezó a descender como organización madre; aunque, al mismo tiempo, se dio el fenómeno de las franquicias, es decir, grupos de menor calado vieron en la organización de bin Laden la oportunidad para crecer y mejorar su «prestigio» si se unían al Emir saudí sacando provecho de la propaganda.

[...] en 2004 el Grupo Salafista para la Predicación y el Combate (GSPC) argelino también inició los contactos para estrechar sus lazos con la organización terrorista de Bin Laden, proceso que culminó en septiembre de 2006 cuando su líder Abdelmalek Drukdel juró fidelidad al dirigente terrorista saudí y cuando, a comienzos de 2007, el GSPC cambió su nombre por Al Qaeda en la Tierra del Magreb Islámico. La adopción de la marca Al Qaeda fue probablemente una maniobra del grupo argelino para recuperar prestigio con el fin de frenar el paulatino declive que en los últimos años viene experimentando la organización y para redirigir hacia sí el flujo de radicales de origen magrebí que en aquellos momentos se estaban alistando en Al Qaeda en Irak. Por su parte, a Al Qaeda 
central la alianza con el GSPC le resultó rentable en términos de fortalecimiento de imagen y realización de atentados a través de grupos regionales con mayor capacidad operativa. (Jordan, 2010).

A pesar de que fueron numerosos los grupos que juraron lealtad a Al Qaeda esto no se vio reflejado en actos que demostraran una creciente fortaleza de la Organización Madre, muy por el contrario. Al Qaeda Central y sus nuevas filiales no lograron capitalizar el aumento de sus militantes, o por lo menos no en nuevos grandes golpes terroristas a nivel global. De allí que sendos analistas de la organización afirmen que el mismo momento culmen marcó el inició de su declive; con la afiliación de otros grupos menores que aprovecharon el momento se inició una serie de actividades terroristas menores por parte de los afiliados, una especie de anarquía dentro de la organización.

$\mathrm{Al}$ Qaeda es una vertiente revolucionaria del islam político contemporáneo. A parte de las manifestaciones moderadas o salafistas, los movimientos como Al Qaeda, Therik e Taliban Pakistan Ansar al Sahria en Tunez y en Libia, entre otros, son parte de lo que podría ser denominado movimiento yihadista global. Tomados en conjunto, estos grupos no forman parte de un todo coherente, aunque $\mathrm{Al}$ Qaeda ha buscado cohesionarlos mediante una ideología y un fin comunes. (Ghotme, 2015).

Al Qaeda sufrió una mutación interna antes y después de los mayores atentados terroristas, perpetrados por la organización, que se recuerdan en la historia de la humanidad. La organización que el mundo conoció no fue la misma después del 11S. Este fue el punto de inflexión que la llevó a globalizarse y generar un sistema de franquicias a partir de lo que era una organización local, como se observa en los gráficos.

En la figura se observa cómo, antes de los atentados de New York, Al Qaeda era una organización terrorista que dependía de la cabeza de una sola persona, del auto denominado Emir Osama bin Laden, quien se erigió como único miembro de la organización con autoridad para decidir sobre esta. Al tiempo que existía un alto consejo también 
dirigido por él, pero integrado por otros como Aiman Al Zawahiri su más cercano colaborador y mano derecha dentro de la organización.

Figura 9. Estructura de Al Qaeda anterior al 11S

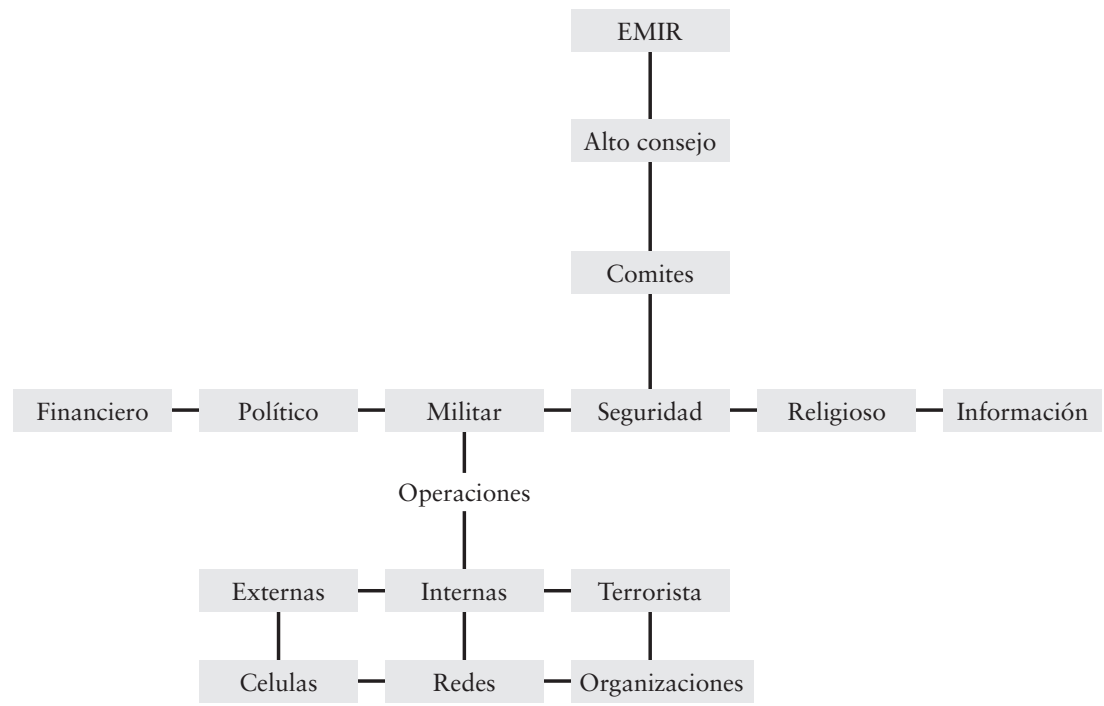

Fuente: La hidra del terror, documental emitido el 20 de septiembre de 2011.

Precisamente, los atentados del 11 de septiembre obligaron a Al Qaeda a modificar su composición interna y funcionamiento, una vez visible a nivel global. Su cambio obedeció a la necesidad de protegerse, las cargas se repartieron y Osama Bin Laden, después de los atentados, se convirtió en un símbolo de la lucha terrorista dentro de su propio grupo. (Rodríguez, 2012).

Posterior a los atentados del 11 de septiembre, como se expuso en la figura 10, Al Qaeda se descentralizó, pasó de ser prácticamente un grupo terrorista nacido en Pakistán, y asentado posteriormente en Afganistán con la protección de los Talibanes del Mulah Omar, a ser una red mundial, integrada por una Cúpula Central dirigida por bin Laden y Al Zawahiri, repartida entre Europa, Estados Unidos, Norte y Sur del África, Asia Central y Latinoamérica, con grupos terroristas aliados o franquicias que surgieron bajo el nombre de Al Qaeda para infundir mayor terror a sus futuras víctimas. 
Después del 11 de septiembre, la financiación de este grupo y sus franquicias, pasó de ser una cuestión de donaciones por parte de millonarios saudíes y del propio bin Laden, a generar un recaudo a través de las mezquitas; y aunque continuó con el uso de los bancos en sus transacciones, se abrió la posibilidad de movilizar hacia Pakistán y Afganistán grandes sumas de dinero de forma regular mediante las mezquitas en Occidente. Estas últimas fueron y son utilizadas como fachadas, pero también para adoctrinar futuros terroristas, con lo cual se amplió el número de simpatizantes, pues vieron en la red un enemigo verdaderamente poderoso para actuar contra Occidente.

Figura 10. Estructura terrorista global posterior al 11S

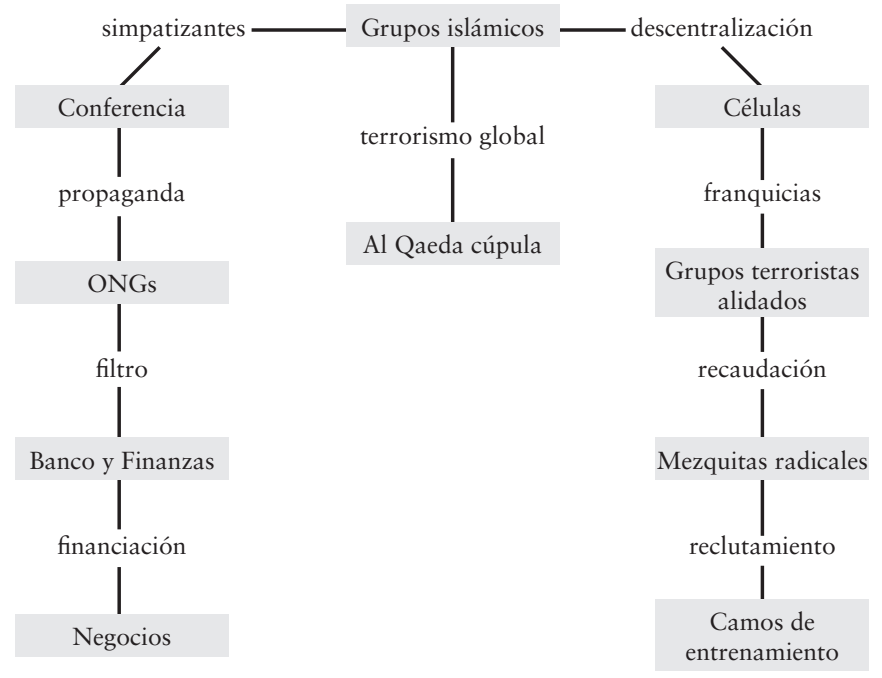

Fuente: La hidra del terror, documental emitido el 20 de septiembre de 2011.

La red se superó a sí misma en propaganda, pues el atentado tuvo repercusiones globales; al mismo tiempo, se sirvió de las nuevas tecnologías para expandir su propaganda global; en consecuencia los campos de entrenamientos crecieron, pues se desbordó el número de simpatizantes de la red terrorista que ahora vieron posible la vulneración de Occidente por parte de grupos radicales islamistas, es decir, Al Qaeda demostró que es posible destruirlo desde adentro y ya no solo desde sus intereses fuera de sus fronteras. El aumento de la propaganda por Internet aumentó el número de sus simpatizantes, incluso en 
Occidente, donde ciudadanos occidentales empezaron a viajar a campos de entrenamientos en Pakistán para luego aplicar el entrenamiento recibido en sus países de origen, los llamados lobos solitarios.

Esta descentralización no fue gratuita y trajo como resultado que Al Qaeda Central ya no pudiese dominar todo lo que tenía que ver son su nombre, pues las franquicias que surgieron bajo su nombre, utilizaron sus propios métodos para subsistir. Puntualmente hablamos del secuestro de ciudadanos occidentales en el Magreb o el Sahel; también del secuestro de embarcaciones en el Índico, por parte de piratas somalíes, que actuaban en nombre de Al Qaeda. En síntesis, la organización terrorista creció después del 11 de septiembre, pero al mismo tiempo Al Qaeda Central dejó de ser la fuente desde la que se emitían las órdenes y se decidía quién, cómo y cuándo serían ejecutadas.

Sin embargo, Al Qaeda hoy es una incógnita sin desentrañar, pues su descenso ha provocado que sean algunas de sus franquicias las que se perfilen como próximas herederas de la fortaleza que una vez ostentó Al Qaeda Central. Hoy por hoy, Aiman Alzawahiri es una figura que no domina ni gobierna la organización, más allá de su propio centro de manado en Paquistán. Así, la fortaleza de la organización actualmente recae sobre el Frente Al-Nusra o Jabhat al-Nusra. Traducido del árabe como "Grupo de Reclutamiento y Apoyo".

Como se ha visto hasta ahora, los grupos yihadistas más importantes desde Al Qaeda al Daesh pasando por Boko Haram o Jabhat al-Nusra y Al-Shabaab -aunque estos dos últimos se integran en $\mathrm{Al}$ Qaeda, tienen su propio protagonismo- entre otros, aspiran a establecer un califato mundial que gobierne sobre todos los musulmanes. El objetivo final es el mismo, aunque la forma o el método de utilizar y establecer los principales elementos del yihadismo, la yihad, el califato y la expansión puede ser distinto [...] Así, mientras Al Qaeda está implantada geográficamente en el mundo a base de franquicias y células yihadistas sin necesidad de control de un espacio territorial, el Daesh y Boko Haram se han postulado, desde el comienzo, por disponer de un territorio propio más consustancial con el término estado. En este sentido, hay más 
similitudes entre el Daesh y Boko Haram con el origen del islam en la Península Arábiga que entre este y Al Qaeda. (Argumosa, 2015).

La situación en Siria ha dejado como heredero principal de la marca Al Qaeda a su filial más poderosa: el Frente Al Nusra.

\section{El heredero poderoso}

La guerra en Siria ha despejado dudas -si es que alguna vez las huboacerca de quién es el nuevo responsable de mantener vigente la marca Al Qaeda en Oriente Próximo y para el mundo, no referimos al Frente Al Nusra, alumno aventajado de la organización madre. Poderoso como no lo fue Al Qaeda Central tras el 11S, ahora lleva sobre sus hombros la fortaleza de no dejar caer la organización y se le adjudica un serio potencial de vencer Daesh en Siria.

Este grupo es un satélite de la creación de Bin Laden (AQ original) y rivaliza con el ISIS, lo hace como un actor sofisticado, inteligente y estratégico en la región donde dispone de una peligrosa libertad operacional no solo en Siria sino también en la zona norte de territorio libanes y partes de Irak. Mientras que ISIS ha anunciado su estado y trata de legitimarlo mediante la conquista de territorios y acciones brutales a quienes se les oponen, Al Nusra ha puesto en marcha el método de fomentar una "revolución religiosa y social" mediante la infiltración silenciosa dentro de las distintas insurgencias locales de los países donde opera y aplica tácticas perfeccionadas y ordenadas por el líder de Al Qaeda, el medico egipcio Ayman Al Zawahiri. (Chaya, 2015).

Al Nusra pertenece al ala Sunní del Islam, al igual que su máximo enemigo, Daesh. Sin embargo, y a pesar del ascenso de este último, esta franquicia sigue fiel a Al Qaeda Central y fortalecida al punto de que ella misma tiene filiales. Es como una hidra, ella siendo una filial ha desarrollado otras filiales que le han jurado lealtad y que hoy combaten a su lado en la guerra siria. El Frente Al Nusra es sin duda 
el grupo terrorista en ascenso que, a mi criterio, reemplaza al Daesh una vez este termine su descenso -que ya ha empezado- toda vez que este último pierde terreno en Siria e Iraq.

Un nuevo grupo armado jura lealtad al Frente al Nusra. El grupo armado Jaish al Muhajireen wal Ansar, más conocido como las Brigadas Muhajireen, ha jurado lealtad al Frente al Nusra, la rama siria de Al Qaeda, según ha informado el Observatorio Sirio para los Derechos Humanos. Las Brigadas Muhajireen, que tienen unos 1.500 combatientes —en su mayoría chechenos, uzbekos y tayikos-, han anunciado su adhesión al Frente al Nusra en un comunicado difundido por Internet. Se trata de un fuerte espaldarazo a Al Qaeda en el contexto de la yihad internacional. Sobre el terreno en la guerra civil siria la pugna entre el Frente Al Nusra y el Estado Islámico se centra en Alepo. Los recién llegados podrían ayudar a decantar la balanza, ya que cuentan con una presencia importante en la ciudad. (Press, 2015).

Los meses posteriores al 11S, tanto el Frente Al Nusra como Al Qaeda Central vienen rompiendo toda lógica dentro de la guerra interna del islam. Es una metamorfosis positiva para las filas del grupo como para Al Qaeda Central que ve fortalecida su franquicia en Siria. El Frente le da un nuevo aire a la organización madre toda vez que no deja caer el nombre de esta; hoy esta franquicia recluta tanto o más que el Daesh en su lucha en Siria. Mientras que a la organización de Al Bagdadí se afilian individuos, al Frente se afilian grupos ya organizados. En los últimos meses el Frente ha conformado con otros grupos rebeldes sirios la alianza conocida como Jaysh Al Fatah o Ejercito de Conquista, a la cual han ingresado más de 1500 muyahidines. Entre los grupos de la alianza se encuentran Harakat Hazm y Ahrar al Sham.

Desde inicios de 2006, la coalición yihadista se ha apoderado de las posiciones claves en el noroeste de la provincia de Idlib ${ }^{12}$ en Siria, donde combate contra rebeldes contrarios a Assad y a la aviación rusa,

12 Ciudad situada en el noroeste de Siria, capital de la Gobernación de Idlib. 
incluyendo la capital provincial. Esta alianza se dio a conocer por canales de televisión británicos y por la cuenta de twitter ${ }^{13}$ del grupo el 6 de mayo de 2016 y amenaza seriamente el poder territorial de Daesh en suelo sirio. La coalición no solo ha reforzado al Frente, proporcionalmente ha conseguido imponerse en lugares donde antes dominaba Daesh; existe además una particularidad y es que ni el Frente Al Nusra en solitario ni ahora la coalición yihadista luchan en tierras que fueran de Siria.

La lucha de la coalición es sin duda una yihad local que también ha ocupado otras provincias de Siria. Alepo y Latakia entran también en los objetivos de donde se tiene que desplazar al Daesh, hasta ahora desde que se iniciara en febrero de 2016 el alto al fuego ${ }^{14}$ por parte de la coalición occidental y de Rusia pactada en Ginebra entre el entonces secretario de Estado Jhon Kerry y el ministro de asuntos exteriores ruso Serguei Lavrov con la participación de los rebeldes sirios. Este pacto no dio los resultados esperados, era simple inferir que, si los «buenos» se retiran, los yihadistas iban a ocupar los lugares abandonados por estos.

El verdadero poder del Frente está aún por descifrar, aunque sin duda hoy es el posible reemplazo del Daesh en Siria, donde tiene la «obligación» de imponerse por ser su cuna. No descarto que el Frente despoje a su contendor yihadista de las zonas que hoy gobierna. Tampoco será fácil para la coalición occidental ni para los rusos lograr «limpiar» el terreno si no se involucra en una operación terrestre. Además, mientras la guerra se concentra en Daesh, que se ve acatado por dos coaliciones (una democrática otra yihadista), el Frente tiene todo el espacio y el tiempo para fortalecerse, porque en Siria se libra

13 @jaysh_alfath

14 Desde las primeras horas del 27 de febrero en Siria entró en vigor el régimen de alto al fuego. El acuerdo fue elaborado por Rusia y EEUU (países copresidentes del Grupo Internacional de apoyo a Siria). El documento firmado no incluye a los grupos terroristas Daesh (autodenominado Estado Islámico) y Frente al Nusra, que también participan en el conflicto en este país árabe. Desde marzo de 2011, Siria se encuentra en medio de una guerra civil. (Sputnik, en línea). Disponible en http://mundo.sputniknews.com/trend/ alto_el_fuego_en_siria_2016/\#ixzz49QH2kzrT 
una guerra contra el primero y esto hace que los segundos queden liberados para actuar de acuerdo a su propia estrategia.

De acuerdo con un informe publicado el jueves en el rotativo británico, gracias al apoyo que ha recibido el Frente Al-Nusra por parte de la denominada coalición internacional que lucha supuestamente contra el grupo takfirí EIIL (Daesh, en árabe), ha podido fortalecer su posición y en los próximos días dará a conocer la creación de un nuevo "emirato islámico" suyo en Siria. Al respecto, Charles Lister, un alto miembro del Instituto de Oriente Medio, ha dicho que después de cinco años del comienzo del conflicto sirio, el Frente Al-Nusra pudo reforzar sus pilares y actualmente los cabecillas de este grupo terrorista buscan crear su propio emirato. (Middle East Council , 22 de mayo de 2016).

Los próximos años no auguran una destrucción total de Al Qaeda, ni de su franquicia más sobresaliente. Es claro que la muerte de bin Laden no afectó del todo a la organización, pues ya desde mucho tiempo atrás él no influía en ella más que como inspiración del pasado, o por lo menos no en las franquicias, como si a Al Qaeda Central. Zawahiri y sus frentes poseen la virtud de la paciencia, toman al tiempo como un aliado, una variable que es propia de su esencia; no se observa lo mismo con el Daesh, cuyo líder va más rápido de lo que pudiera y esto, a futuro, traerá mutaciones necesarias en el grupo, sea porque la coalición occidental-rusa los obliga o porque el Frente lo debilita militarmente al punto de mutar en varios grupos. 
